Journal of the Electrochemical Society, 1991, Volume 138, Issue 1, Pages 337-338.

ISSN: 0013-4651

DOI: $10.1149 / 1.2085572$

http://www.electrochem.org/

http://scitation.aip.org/getpdf/servlet/GetPDFServlet?filetype=pdf\&id=JESOAN000138000001000337000

001\&idtype=cvips\&prog=normal

(C) The Electrochemical Society, Inc.1991. All rights reserved. Except as provided under U.S. copyright law, this work may not be reproduced, resold, distributed, or modified without the express permission of

The Electrochemical Society (ECS). The archival version of this work was published in Journal of the

Electrochemical Society, 1991, Volume 138, Issue 1, Pages 337-338.

\title{
In Situ X-Ray Absorption Study of Chromium Valency Changes in Passive Oxides on Sputtered AICr Thin Films under Electrochemical Control
}

\author{
A. J. Davenport* and H. S. Isaacs* \\ Department of Applied Science, Brookhaven National Laboratory, Upton, New York \\ G. S. Frankel,* A. G. Schrott, C. V. Jahnes, and M. A. Russak \\ IBM Research Division, T.J. Watson Research Center, Yorktown Heights, New York \\ *Electrochemical Society Active Member.
}

The valence state of chromium in passive films on metals is conventionally studied using surface analytical techniques such as AES and XPS. As these techniques involve electron detection, they can only be carried out ex situ in UHV after electrochemical treatment. X-ray absorption spectroscopy can be used to determine both valency and structural environment and, as only x-rays are involved, measurements can be carried out in air or in situ in an electrochemical cell. Recent in situ studies of passivity have used EXAFS (Extended X-ray Absorption Fine Structure) to determine passive film structure [1-4]. In this communication, we report on an in situ XANES (Xray Absorption Near Edge Structure) study of reversible changes in the valence state of chromium in passive films,

A recent ex situ XANES experiment [5] showed that an oxide film containing $\mathrm{Cr}(\mathrm{VI})$ can be formed on AlCr alloys by polarization to high potentials in a borate buffer solution. This chromate was reduced to the +3 state at a low potential and then reoxidized to the +6 state by polarizing again to the high potential. In this communication we report similar results measured in situ which demonstrate the applicability of XANES to simultaneous valency and electrochemical measurements. As a single fixed specimen is used throughout the experiment, quantitative information on the dissolution of chromium is available.

\section{EXPERIMENTAL}

Around the chromium $\mathrm{K}$ edge $(\sim 6 \mathrm{keV})$, the absorption length of $\mathrm{x}$-rays in water is of the order of $1 \mathrm{~mm}$ which complicates cell design. The electrochemical cell is shown in Fig.l. It is based on that used by Kerkar et al. [1] which allows both electrochemical control and surface sensitivity. The electrode consists of a thin Mylar window $(\sim 6 \mu \mathrm{m})$ on which has been sputtered $\sim 100 \AA$ of Ta (in order to maintain electrical contact) and $\sim 20 \mathrm{~A}$ of $\mathrm{Al}-12 \% \mathrm{Cr}$. The thin alloy deposit is used so that most of it is oxidized when the 
passive layer is formed in order to minimize the signal from metallic chromium in the alloy. The electrode is in contact with bulk solution giving good electrochemical control.

A mercurous sulfate reference electrode was used (MSE, $656 \mathrm{mV}$ vs. SHE) and the solution was $0.5 \mathrm{M} \mathrm{H}_{3} \mathrm{BO}_{3}+0.05 \mathrm{M} \mathrm{Na}_{2} \mathrm{~B}_{4} 0_{7}$. Monochromatic $\mathrm{x}$-rays were incident at $\sim 45^{\circ}$ to the electrode surface and $\mathrm{Cr} \mathrm{K} \alpha$ radiation was detected with a 13 element solid state detector (Canberra [6]) placed at $90^{\circ}$ to the incident x-rays. Such an energydiscriminating detector is required in order to detect the small chromium fluorescence signal against the high background of incident radiation scattered by the cell, especially by the solution.

$\mathrm{X}$-ray absorption edges of standard compounds, fine powders of $\mathrm{K}_{2} \mathrm{CrO}_{4},(\mathrm{Cr}(\mathrm{VI}))$ and $\mathrm{Cr}_{2} \mathrm{O}_{3}(\mathrm{Cr}(\mathrm{III}))$, and chromium metal foil were measured in conventional transmission geometry using an ionization chamber detector.

\section{RESULTS AND DISCUSSION}

The solid lines in Fig.2 show a series of absorption spectra measured in situ for chromium in the passive film on the sputtered $\mathrm{Al}-12 \mathrm{Cr}$ alloy. A linear background extrapolated from the pre-edge section has been subtracted. The spectra are shown on the same scale but have been displaced vertically for ease of viewing. The broken lines show the three standard compounds for comparison. These have been normalized to give the same edge height as the experimental data. These curves show that the position of the absorption edge moves to higher energies as the valence state of chromium increases. Curve (b) $\left(\mathrm{K}_{2} \mathrm{CrO}_{4}\right)$ shows the distinctive sharp peak below the edge which is characteristic of tetrahedrally coordinated $\mathrm{Cr}(\mathrm{VI})$ compounds. For a pure 6-valent compound, the height of the pre-edge peak is approximately the same as the height of the edge.

Curve (a) (solid line) shows the spectrum measured after the sample was immersed at open circuit for 12 minutes. The position of the edge coincides with that of chromium metal (broken line). Curve (b) shows the spectrum measured 7 minutes after the potential was stepped to $2 \mathrm{~V}(\mathrm{MSE})$. From the height of the pre-edge peak and the position of the edge, it can be seen that about half the chromium is in the +6 valence state. Comparison of the edge heights of (a) and (b) show that there is little loss of chromium when it is oxidized in the film to the +6 valence state despite the solubility of chromate ions.

Curve (c) shows the spectrum measured after the specimen is then reduced at $1.5 \mathrm{~V}$ (MSE) for 6 minutes. Comparison with the $\mathrm{Cr}_{2} \mathrm{O}_{3}$ standard (broken line) indicates that the chromium is in the +3 valent state with no +6 present. The height of the edge is similar for curves (a), (b), and (c) indicating that the oxidation-reduction cycle has resulted in insignificant dissolution of chromium.

\section{CONCLUSION}

X-ray absorption can be used to make in situ valence measurements of species in passive films under electrochemical control. This technique has been used to show that the valence state of chromium in passive films on a sputtered $\mathrm{AlCr}$ alloy can be changed reversibly without dissolution of 6-valent chromium. 


\section{ACKNOWLEDGEMENTS}

This work was carried out in part under the auspices of the US Department of Energy, Division of Materials Sciences, Office of Basic Energy Science under Contract No. DE-AC02-76CH00016. XANES measurements were carried out at the National Synchrotron Light Source Beamline X19A. The authors are grateful to Dr. S. P. Cramer for his assistance with the Canberra detector.

\section{REFERENCES}

1 M. Kerkar, J. Robinson, and A. J. Forty, Faraday Discuss. Chem. Soc. 89, (1990) in press.

2 G. G. Long, J. Kruger, and M. Kuriyama, "Passivity of Metals and Semiconductors" p. 139, (ed. M Froment), Elsevier, Amsterdam (1983).

3 R. W. Hoffman, ibid., p. 147.

4 L. Bosio, R. Cortes, P. Delichere, M. Froment, and S. Joiret, Surf. Interface Anal. 12, 380 (1988).

5 G. S. Frankel, A. J. Davenport, H. S. Isaacs, A. G. Schrott, C. V. Jahnes and M. A. Russak, Extended Abstracts 90-1, No.205, Electrochemical Society Spring Meeting, Montreal, Canada (1990).

6 S. P. Cramer, O. Tench, M. Yocum and G. N. George, Nucl. Instr. Methods A266, 586 (1988)

Manuscript received Sept. 7, 1990. Brookhaven National Laboratory assisted in meeting the publication costs of this article.

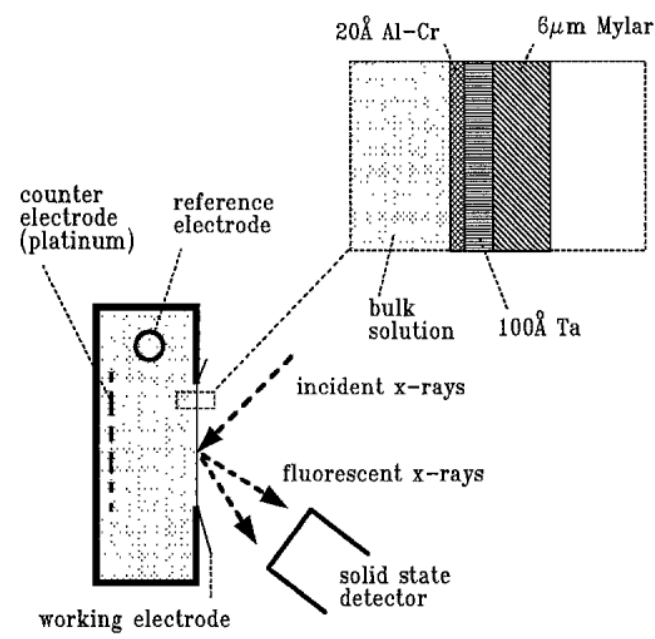

Fig.l Schematic plan of experimental apparatus. 


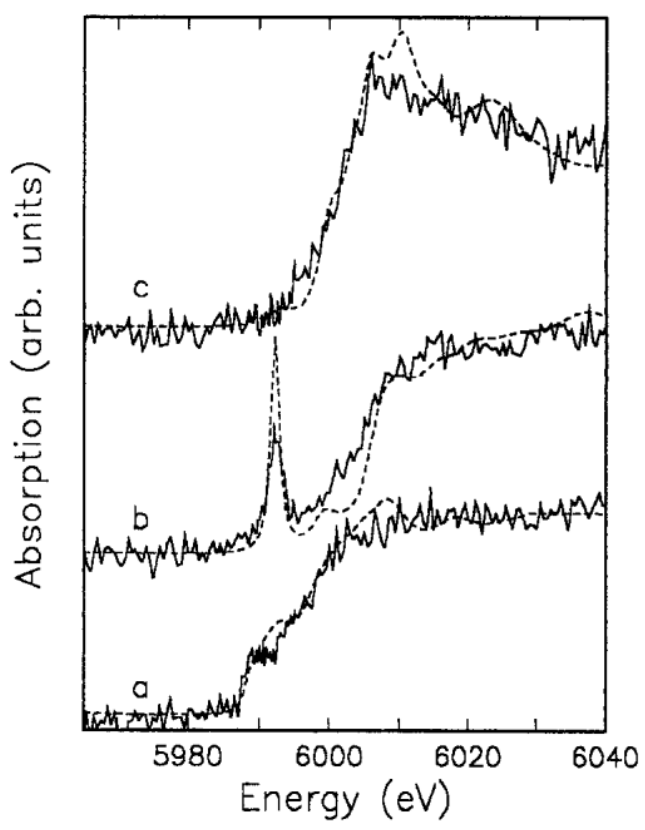

Fig.2 X-ray absorption spectra measured in situ for a $\mathrm{Al}-12 \mathrm{Cr}$ alloy (a) at open circuit, (b) after 7 minutes at $2 \mathrm{~V}$ (MSE), (c) after 6 minutes at $-1.5 \mathrm{~V}$ (MSE) (solid lines). The broken lines show standard compounds measured in transmission: (a) $\mathrm{Cr}$ metal, (b) $\mathrm{K}_{2} \mathrm{CrO}_{4}$ powder and (c) $\mathrm{Cr}_{2} \mathrm{O}_{3}$ powder. 